Original Article

\title{
Relationship of Ergonomics, Lifestyle and Job Satisfaction among Sonographers in Riyadh, KSA
}

\author{
Uzma Zaidi, Lina Fahmi Hammad, Salwa Saad Awad, Safaa Mostafa Ali Elkholi, \\ Hind Diouri Qasem
}

ABSTRACT

OBJECTIVE: The objective of the study is to investigate the relationship between ergonomics, lifestyle and job satisfaction among Sonographers in Riyadh KSA.

METHODOLOGY: Predictive Correlational Design study was carried out at Riyadh KSA. Ergonomics were measured by administering subscale of work context derived from the Work Design Questionnaire. Whereas, Job Stress Scale was used to measure the level of job satisfaction. Self-rated scales measured lifestyle variables included perceived health, average sleep and frequency of exercise. Data was collected through survey research forms.

RESULTS: Results revealed the significant relationship between ergonomics and job satisfaction $(r=0.251, p=0.002)$. Among lifestyle variables, perceived good health $(r=0.214, p=0.008)$ and sleep $(r=0.242$. $p=0.003)$ were found positively related to job satisfaction. Whereas, the strong positive correlation was found between ergonomics and frequency of physical activity ( $r=0.255, p=0.005)$. No significant difference was found between male and female Sonographers on ergonomics and job satisfaction except sub-variables of lifestyle.

CONCLUSION: The findings of this study contributed to evaluating the working condition of sonographers and their job satisfaction. It was found that appropriate ergonomics can predict job satisfaction among sonographers. Effective strategies for better utilization of work settings as well as achieving satisfaction in work through lifestyle was discussed to enhance the performance of sonographers.

Keywords: Ergonomics, Job satisfaction, lifestyle, Sonographers

This article may be cited as: Zaidi U, Hammad LF, Awad SS, Elkholi SMA, Qasem HD. Relationship of Ergonomics, lifestyle and Job Satisfaction among Sonographers in Riyadh, KSA. J Liaquat Uni Med Health Sci. 2018;17(03):127-34. doi: 10.22442/jlumhs.181730564

\section{INTRODUCTION}

Healthcare professionals are exposed to the risk of work stress due to many reasons, that can affect their mental health status ${ }^{1}$. Several studies have explored various kinds of mental health aspects that formed by the work design and work structure ${ }^{2}$. Working context can enhance and impair mental health simultaneous$1 y^{3}$. Health professionals particularly sonographers, if not having excellent work context can suffer from several health issues, for example, musculoskeletal injuries $(\mathrm{MSI})^{4}$. The literature revealed that health professionals face an elevated level of stress which leads to physical and psychological disturbances, for instance, low self-esteem, low motivation, low mood, somatic complaints, sleep disturbances, and burnout ${ }^{5}$. This high level of stress among health professionals' grounds for both individual and organizational problems. Moreover, it can negatively affect the standards of the expected health care services. Theories and studies on human factors and ergonomics have proved the influence of stress on performance and human-machine interaction ${ }^{6-8}$.

Job satisfaction has been considered one of the important aspect to achieve the excellence in work among health professionals ${ }^{9}$. Greater job satisfaction among healthcare providers is found related to the quality of care, patient satisfaction, and expenditure of care $^{10}$. A study revealed that a high level of job satisfaction was found among fellow graduate students of ultrasound ${ }^{11}$. On the other hand, ergonomics can also create a sense of satisfaction or dissatisfaction. A study by Gibbs $\mathrm{V}$ and Edwards $\mathrm{H}^{12}$ is evident that those sonographers who were following instructions to use equipment properly and having job 
satisfaction were not exposed to $\mathrm{MSI}^{12}$.

Work stress is one of the elements that negatively effect the performance of healthcare providers. Many reasons can cause it. Sometimes it is related to personal characteristics, for instance, habits, lifestyle, personal incompetence and perceptual predispositions. Sometimes it arises from external sources, for instance, social interactions at the workplace that have a significant effect on the quality of life. Sometimes work context including ergonomics, equipment used, working conditions provoke stress $^{13,14}$. Health care professionals cannot provide the best of their potentials if the level of stress is high due to either reason ${ }^{9,14}$. Szalma, in his article explained the relationship of ergonomic with human factor regarding motivation and satisfaction ${ }^{15}$.

Sonographers as professional health care providers have reported a high prevalence of work-related musculoskeletal pain and discomfort ${ }^{16-19}$. The physical demand for the work of the sonographers requires sonographers to be seated all through the investigation $^{20}$. Bedside examination is also tireless, as the sonographer must adjust his or her working position to the bedside condition ${ }^{21}$. Other researchers also studied the stress-related risk factors such as disproportionate workload, time pressure, tough or difficult tasks, insufficient rest breaks, monotony in conducting the same tasks, and the physically poor work environment conditions are considered as additional factors affecting health care professionals ${ }^{22}$. Job-related stress is common among health care providers rather than any other profession, i.e. the increased workload, work environmental factors and work disparities ${ }^{23}$. Radiologist in New Zealand has experienced reduced levels of stress in the private clinics rather than their counterparts in the public ones $^{24}$. This stress is beside their exposure to distinctive kinds of stressors which are mainly the intensive contact with patients who undergo pains and death $^{25}$. Studies showed that people suffered from occupational stress have also suffered from poor psychological well-being ${ }^{26}$. Work stress and dissatisfaction of job might be greater among female professionals or sonographers due to the family, social and professional demands ${ }^{27}$.

The literature has emphasised that in response to stress people get to engage in unhealthy behaviours, such as poor dietary habits or a less regular exercise, as a means of emotion-focused coping strategies ${ }^{1}$. It has been suggested that there is a link between work stress and leisure-time physical activity ${ }^{2,3}$. High stress could decrease the readiness or the interest of the employees to get involved in regular exercise and other physical activity ${ }^{16}$. Hughes and Rogers reported unhealthy eating habits and less engagement in physical exercise among health professionals due to stressful work schedule ${ }^{28}$.

The working conditions are representing the central aspects that induce the level of stress ${ }^{1}$. Ergonomics determine the satisfaction level of workers and their level of stress ${ }^{29}$. For the clinical intervention to get effective outcomes; the personal characteristics of the healthcare providers are significantly related to the positive change that these healthcare providers must leave in promoting the health of their clients. The current study reflects on the outcomes of an investigation that explores the sonographers' work experiences in the work environment and its relations to mental health. Furthermore, various lifestyles have been studied about work context and job satisfaction. After reviewing the literature, the following hypothesis was formulated as, "There will be a significant relationship between work context, lifestyle and job satisfaction for sonographers in Riyadh". Additionally, "There will be a significant difference between male and female sonographers on work context and job satisfaction level".

\section{METHODOLOGY}

The present study used predictive correlational research design. The research method applied is quantitative. Survey technique was used including two standardized self-report questionnaires and one rating scale. The study was conducted to investigate the relationship of work context, lifestyle and job satisfaction among sonographers in Riyadh during May 2016-April 2017. INCLUSION / EXCLUSION CRITERIA: The sample of this study was comprised of 153 (male=33, female=120) sonographers of Riyadh. Participants were approached in governmental as well as private sectors. Qualified sonographers appointed at various hospitals were included. Minimum work experience was at least for six months. Those sonographers having work experience of less than 6 months were excluded. This criterion for the tenure of 6 months was considered to avoid adjustment problems.

MEASURES:

i. Rating scale for lifestyle: A brief rating scale was derived to measure the lifestyle ${ }^{30}$. It included three items of perceived health (Ranging from Poor $=1$; to Excellent $=5$ ), the frequency of physical activity (never=1 to every day=5) and average sleep (1-5).

ii. Work Context Subscale is derived from Work Design Questionnaire that was developed by Morgeson and Humphrey in $2006^{31}$. This scale contains 14 items altogether. Work Context Subscale 
has further 4 domains namely Ergonomics (3 items), Physical Demand (3 items), Work Conditions (5 items), and Equipment Use (3 items). This instrument uses a 5-point Likert scale. Responses range from strongly disagree (score 1 ) to strongly agree (score 5). The third item of ergonomics domain has reversed scoring. A higher score indicates satisfaction with work setting.

iii. Work Stress Scale measures the level of job satisfaction and opportunity for expression and achievement ${ }^{32}$. It has 20 items. It can be scored as yes or no (0 and 1). Every yes reply scored one (1) score. More than 16 has been considered as satisfaction. Meanwhile, less than ten (10) scores signify stress at the job.

ETHICAL CONSIDERATION: All the ethical considerations were fulfilled before conducting the study. Ethical approval from the Departmental scientific sub-committee and Research Ethical committee of the College of Health and Rehabilitation Sciences (application code: Z-F004), Princes Nourah Bint Abdulrahman University was sought. Before approaching participants, a letter explained the purpose of the study was sent to the hospital administration for getting permission. Consent forms were provided to the subjects to indicate their willingness to participate in the study and to gather demographic information. Participants were assured about the confidentiality of their information. Then standardized scales were administered to individuals. Data were collected by using both means of individual administration and by online survey forms.

STATISTICAL ANALYSIS: Collected data were analyzed by using SPSS (V. 24). Pearson coefficient of correlation was conducted to measure the relationship between lifestyle variables with work context and job satisfaction. Regression analysis was used to measure the predictive association of work context, lifestyle and job satisfaction among sonographers. Additionally, one sample t-test was calculated to confirm the tendency of scores in the group. Lastly, for comparison purpose among male and female sonographers on the variables of work context, lifestyle and job satisfaction, independent sample t-test was calculated.

\section{RESULTS}

Results in Table $I$ is showing that most of the sonographers among respondents belong to less than 40 years of age (83\%). The majority of the group of participants were having the education of Bachelors $(82 \%)$. Most of the sonographers in the sample were having work experience of $1-10$ years $(77 \%)$.

Regression analysis was conducted to measure the predictive association of work context, lifestyle and job satisfaction. Initially, Pearson's Correlation revealed that work context was significantly correlated with job satisfaction $(r=0.251,<0.01)$ among sonographers. Results in (Table II) indicated that work context was significantly correlated with the high frequency of exercise $(r=0.225,<0.01)$ among lifestyle. Whereas, perceived status of health $(r=0.214,<0.01)$ and average sleep $(r=0.242,<0.01)$ were found significantly correlated with job satisfaction respectively. Furthermore, regression analysis confirmed the predictive relationship $F(1,151)=5.679, \quad p<0.000$, $R^{2}=0.133$ of work context and job satisfaction. Among lifestyles average sleep was also found as a predictor of job satisfaction.

Pearson's Correlation was conducted to measure the relationship of subscales of work context with the sum of scores. Results in (Table III) indicated that the subscales of work context are having inter consistency with the total score of the work context. Subscale of ergonomics ( $r=0.580, p<0.01)$, physical demand $(r=0.499, p<0.01)$, work conditions $(r=0.781, p<$ $0.01)$ and equipment use $(r=.689, p<.01)$ were found strongly correlated with total work context scores. Further job satisfaction scores also found to have highly significant correlation with subscale of work condition $(r=0.261, p<0.01)$ and ergonomics $(r=0.201, p<$ 0.05 ). Results are also approving that there was a significant positive correlation between work context and job satisfaction $(r=0.251, p<0.01)$ among sonographers.

One sample t-test was conducted to analyse the comparative results for the variables of work context, lifestyle and job satisfaction. Results (table IV) indicated that sonographers of Riyadh scored high on both variables that showed high satisfaction toward their job context $(\mathrm{t}=78.66, \mathrm{p}<0.05)$ and toward their job satisfaction $(t=10.59, p<0.05)$. Moreover, the mean score on job satisfaction is higher than the cutoff point that confirms the higher job satisfaction level of sonographers in general $(M=14.07>10)$.

Independent sample t-test was conducted to permit comparison across domains. Results (Table V) shows that there is no statistically significant difference between male and female sonographers on the variables of work context and job satisfaction. Although cut off score for job satisfaction is ten (10), but male sonographers $(M=15.36)$ were found more satisfied with their job as compared to female sonographers (13.72). Among lifestyles, female sonographers scored high on physical activity $(t=3.302, p<0.05)$ and male scored high on average sleep $(t=2.161, p<0.5)$. 
Ergonomics and Sonographers in Riyadh, KSA

TABLE I: DESCRIPTIVE STATISTICS

\begin{tabular}{|l|l|l|l|l|}
\hline Variables & $\boldsymbol{f}$ & $\boldsymbol{P}$ & Sd & $\boldsymbol{M}$ \\
\hline Age & 127 & $83 \%$ & .377 & 1.17 \\
\hline $18-40$ years & 26 & $17 \%$ & - & - \\
\hline $40-60$ years & 125 & $82 \%$ & - & - \\
\hline Education & 19 & $12 \%$ & - & - \\
\hline BS & 19 & $6 \%$ & - & - \\
\hline Diploma & & & \\
\hline Masters or above & 117 & $77 \%$ & .426 & 1.24 \\
\hline Work experience & 36 & $23 \%$ & - & - \\
\hline $1-10$ years
\end{tabular}

TABLE II: REGRESSION ANALYSIS

\begin{tabular}{|l|c|c|c|c|c|}
\hline Variables & Health & $\begin{array}{c}\text { Physical } \\
\text { activity }\end{array}$ & Sleep & $\begin{array}{c}\text { Work } \\
\text { Context }\end{array}$ & $\begin{array}{c}\text { Job satis- } \\
\text { faction }\end{array}$ \\
\hline Health & - & - & - & - & - \\
\hline $\begin{array}{l}\text { Physical } \\
\text { activity }\end{array}$ & -.116 & - & - & - & - \\
\hline Sleep & $.250^{* *}$ & -.066 & - & - & - \\
\hline $\begin{array}{l}\text { Work } \\
\text { Context }\end{array}$ & .139 & $.225^{* *}$ & .053 & - & - \\
\hline $\begin{array}{l}\text { Job } \\
\text { satisfaction }\end{array}$ & $.214^{* *}$ & -.109 & $.242^{* *}$ & $.251^{* *}$ & - \\
\hline
\end{tabular}

${ }^{* *} p<.01,{ }^{*} p<.05$

Model Summery of Multiple Regression Analysis

\begin{tabular}{|c|c|c|c|}
\hline Model & $\mathbf{R}$ & $\mathbf{R}^{2}$ & $\mathbf{R}^{2}{ }_{\text {Adjusted }}$ \\
\hline 1 & $.365^{\mathrm{a}}$ & .133 & .110 \\
\hline
\end{tabular}

a. Predictors: (Constant), Ergonomics, Health, Physical activity, Sleep

ANOVA $^{a}$ for the Regression Equation

\begin{tabular}{|l|l|l|l|l|l|}
\hline \multicolumn{1}{|c|}{ Model } & \multicolumn{1}{c|}{ Ss } & \multicolumn{1}{c|}{$\boldsymbol{d f}$} & \multicolumn{1}{c|}{ MS } & \multicolumn{1}{c|}{$\boldsymbol{F}$} & \multicolumn{1}{c|}{ P } \\
\hline Regression & 457.521 & 4 & 114.380 & $5.679^{* *}$ & $.000^{\mathrm{b}}$ \\
\hline Residual & 2980.689 & 148 & 20.140 & - & - \\
\hline Total & 3438.209 & 152 & - & - & - \\
\hline
\end{tabular}

${ }^{* *} p<0.01$

a. Dependent Variable: Job satisfaction

b. Predictors: (Constant), Ergonomics, Health, Physical activity, Sleep

Beta Coefficients for predictors of Job satisfaction among sonographers

\begin{tabular}{|l|c|c|c|c|c|}
\hline Predictors & B & SE B & $\boldsymbol{\beta}$ & $\boldsymbol{t}$ & $\boldsymbol{P}$ \\
\hline (Constant) & .938 & 3.486 & - & .269 & .788 \\
\hline Work Context & .160 & .059 & .215 & $2.724^{* *}$ & .007 \\
\hline Health & .843 & .514 & .131 & 1.641 & .103 \\
\hline $\begin{array}{l}\text { Physical } \\
\text { activity }\end{array}$ & -.116 & .284 & -.032 & -.410 & .682 \\
\hline Sleep & .850 & .344 & .195 & $2.471^{* *}$ & .015 \\
\hline
\end{tabular}

${ }^{* *} p<0.01$

TABLE III: PEARSON CORRELATION MATRIX OF SUBSCALES OF WORK CONTEXT

\begin{tabular}{|l|c|c|c|c|c|c|}
\hline \multicolumn{1}{|c|}{ Variables } & (1) & (2) & (3) & (4) & (5) & $\mathbf{( 6 )}$ \\
\hline (1) Ergonomics & - & - & - & - & - & - \\
\hline $\begin{array}{l}\text { (2) } \begin{array}{c}\text { Physical } \\
\text { demand }\end{array} \\
\text { (3) Work conditions }\end{array}$ & $.296^{* *}$ & .071 & - & - & - & - \\
\hline (4) Equipment use & $.243^{* *}$ & $.302^{* *}$ & $.320^{* *}$ & - & - & - \\
\hline (5) Work Context & $.580^{* *}$ & $.499^{* *}$ & $.781^{* *}$ & $.689^{* *}$ & - & - \\
\hline (6) Job satisfaction & $.201^{*}$ & .025 & $.261^{* *}$ & .114 & $.251^{* *}$ & - \\
\hline$* * p<01{ }^{*} p<.05$
\end{tabular}

${ }^{* *} p<.01,{ }^{*} p<.05$

\section{DISCUSSION}

Work design or work context represent the satisfaction and self-motivational aspect of workers ${ }^{33}$. Further more, it is related to their efficiency and level of performance. If the person finds working environment or context appropriate to work that will increase the motivation, satisfaction and performance level. Work context including standardized ergonomics, appropriate physical workload, good working conditions, and the use of equipment under controlled procedures, can enhance the work efficiency ${ }^{34}$. On the other hand, lifestyle has been found impacting the physical and psychological health of health care professionals ${ }^{28}$. In referring to the sonographers, healthy lifestyle of physical exercise was found correlated with satisfaction to work context (table II). It is similar to previous studies that addressed the issue of reducing the chances of injuries by providing recommendations to improve the lifestyle of sonographers. Morton and Delf in 2008, have discussed various themes related to musculoskeletal injury among sonographers and suggested that muscle strengthening exercises, stretches and relaxing can help to prevent injuries ${ }^{13}$. Other studies also recommended raising the awareness of sonographers due to the high ratio of MSI occurrence, ergonomics, psychological effects on health ${ }^{4,16}$. Moreover, average sleep and perception of good health were found correlated with job satisfaction. It is 
Uzma Zaidi, Lina Fahmi Hammad, Salwa Saad Awad, Safaa Mostafa Ali Elkholi, Hind Diouri Qasem

TABLE IV: ONE-SAMPLE T-TEST

\begin{tabular}{|c|c|c|c|c|c|c|c|}
\hline Variables & $\mathbf{M}$ & SD & $\mathbf{n}$ & $\begin{array}{c}\text { Comparison } \\
\text { Value }\end{array}$ & $\begin{array}{l}95 \% \mathrm{Cl} \text { for Mean } \\
\text { Difference }\end{array}$ & $\mathbf{t}$ & df \\
\hline Work context & 50.65 & 1.391 & 153 & - & $50.647,51.67$ & $78.66^{*}$ & 152 \\
\hline Health & 3.32 & .740 & 153 & - & $-6.80,-6.56$ & -111.6 & \\
\hline Physical activity & 2.03 & 1.323 & 153 & - & $-8.19,-7.76$ & -74.57 & \\
\hline Sleep & 2.88 & 1.094 & 153 & - & $-7.29,-6.94$ & -80.48 & \\
\hline Job satisfaction & 14.07 & 2.756 & 153 & 10 & $13.31,14.83$ & $10.59^{*}$ & 152 \\
\hline
\end{tabular}

${ }^{*} p<.05$

TABLE V: GENDER DIFFERENCE

\begin{tabular}{|c|c|c|c|c|c|c|c|}
\hline \multirow{2}{*}{ Variables } & \multirow{2}{*}{ Gender } & \multicolumn{4}{|c|}{ Group } & \multirow{2}{*}{$t$} & \multirow{2}{*}{$p$} \\
\hline & & $M$ & $S D$ & $N$ & Comparison Value & & \\
\hline \multirow[t]{2}{*}{ Work context } & Male & 51.21 & 1.256 & 33 & \multirow{2}{*}{ - } & \multirow{2}{*}{.572} & \multirow{2}{*}{.568} \\
\hline & Female & 50.49 & 1.835 & 120 & & & \\
\hline \multirow{2}{*}{ Health } & Male & 3.52 & .667 & 33 & \multirow{2}{*}{ - } & \multirow{2}{*}{1.791} & \multirow{2}{*}{.088} \\
\hline & Female & 3.27 & .753 & 120 & & & \\
\hline Physical activity & $\begin{array}{l}\text { Male } \\
\text { Female }\end{array}$ & $\begin{array}{l}1.55 \\
2.16\end{array}$ & $\begin{array}{l}.905 \\
1.390\end{array}$ & \begin{tabular}{|l|}
33 \\
120
\end{tabular} & - & $-3.302^{* *}$ & .003 \\
\hline Sleep & \begin{tabular}{|l} 
Male \\
Female
\end{tabular} & $\begin{array}{l}3.24 \\
2.78\end{array}$ & \begin{tabular}{|l|}
1.173 \\
1.055
\end{tabular} & \begin{tabular}{|l|}
33 \\
120
\end{tabular} & - & $2.161^{*}$ & .032 \\
\hline \multirow{2}{*}{ Job satisfaction } & Male & 15.36 & 2.869 & 33 & \multirow{2}{*}{10} & \multirow{2}{*}{1.774} & \multirow{2}{*}{.078} \\
\hline & Females & 13.72 & 2.629 & 120 & & & \\
\hline
\end{tabular}

consistent with previous studies, where sonographers perceived that their life had been compromised by their work and impact upon their sleep patterns ${ }^{35}$. Predictive association of work context and lifestyle with job satisfaction in this study strengthened the results.

All the factors in work contexts are equally important and impact upon work efficacy. Ergonomics allow the sonographers to complete their tasks in an appropriate manner that can help to maintain their physical health and protect them from work-related injuries. Therefore, the factor of ergonomic is found having $(33 \%)$ effect on satisfaction with work context (table III). The second variable of physical demand is explaining the load of work and explaining the variation of $24 \%$. Working condition was found the most influencing factor with the variation of $61 \%$. The fourth variable was equipment use that is related to technology and complexity. This variable was found having the second greatest impact factor $(47 \%)$. This result has been statistically supported in this current study. All the subscales of the work context were highly correlated with total scores. It represents that sonographers in Riyadh were experiencing a high quality of working environment under standardized application of the procedural protocol. It was found in previous studies that if health professionals did not have good work settings that would affect their satisfaction level and performance ${ }^{29}$. Additionally, another result is valuable to explain regarding the significant relationship of job satisfaction with work conditions and ergonomics. These variables were found contributing to the satisfaction level or alternately decreasing the stress level among sonographers. It is worth mentioning about an additional analysis (table IV) that is presenting that all the sonographers in the study scored high on work context and job satisfaction. It further confirms the majority of the sonographers are having the adequate working environment and having satisfaction in their job as well.

Although in previous studies it was found that female sonographers were having higher occurrences of MSI thus it was hypothesized to measure the difference of satisfaction with work context and job among male and female sonographers. However, no significant difference was found in both of the variables (table $\mathrm{V}$ ). It can be explained by having less number of male 
participant in the study. Whereas, a difference in mean scores is providing some valuable results. Mean score of male sonographers is high on satisfaction with the working environment as well as on job satisfaction. On job satisfaction, both groups scored higher mean than the comparison value. It can be explained due to conducting the standardized procedure of protocol approved by the Saudi Ministry of Health for all sonographer that yields no difference. Among lifestyles, two of the variables of physical activity and sleep were found statistically significant. Female sonographer scored higher on physical activity as compared to male sonographers. It represents the awareness of health factors of female sonographers. Whereas, male sonographers scored higher on average sleep. Although it can be assumed that professional female has more responsibilities of home ${ }^{36}$, but it can't be generalized due to unequal sample proportion.

There are some limitations to the study. The respondents of this current study were predominantly female sonographers which demand increasing male sonographers in future similar studies to compare the different responses between males and female sonographers. A similar study should be extended to other regions in the Kingdom of Saudi Arabia to obtain a broader interpretation of the factors that influence sonographers' psychophysiological wellbeing as well as job satisfaction. Furthermore, the sonographers' job satisfaction and overall organizational contexts mainly the psychological correlates of work context particularly the social and interpersonal interaction among sonographers need to be investigated for specific socio-economic and development purposes. The lifestyle of diet, work/rest cycle, taking care of health and smoking (health-harming behaviours) can be included.

\section{CONCLUSIONS}

It can be concluded that ergonomics is directly related to job satisfaction among sonographers. It was found that if sonographers are satisfied with ergonomics, physical demand of work, work conditions and equipment use it may lead toward the satisfaction of work context, increased motivation and productivity. On the other hand, satisfaction with work context can lead toward job or lesser levels of stress. Some essential life-styles were highlighted in this study. Physical exercise was found correlated with ergonomics, whereas, average sleep and perception of health were correlated with job satisfaction. Specific, considerations should be given to regulate the extreme work assignments and time pressures as it has been proved from the literature that these factors may augment the job dissatisfaction and increase or worsen the emotional/psychological reactions of sonographers and might lead to stress and MSI. There was no gender-based difference found on ergonomics and job satisfaction. Among lifestyle variables, female sonographers were found more actively engaged in physical exercise and male were having better sleep patterns. This study has also recommended that healthcare settings must work to create conducive work conditions for its employees that can enhance employees' satisfaction with autonomy, competence, and affiliation.

\section{RECOMMENDATIONS}

- To improve the work context for sonographers, it is recommended to provide hands-on, multidisciplinary training programs to offer essential information for machine users experience through ongoing proven evaluation techniques.

- It is also recommended for sonographers to demonstrate several bodily exercises for example; stretching techniques to enable them to avoid repetitive strain injuries.

- It is essential to take frequent breaks at work, to get up and walk or stretch, to break the extended sitting cycle and to reduce the severe effects of sitting.

- Awareness regarding work/rest cycle to administrative staff and sonographers can increase the satisfaction level towards work.

\section{CONFLICTS OF INTEREST}

The authors declare no conflict of interest. This research did not receive any specific grant for research work or to cover the cost to publish in open access from funding agencies.

\section{REFERENCES}

1. Koinis A, Giannou V, Drantaki V, Angelaina S, Stratou E, Saridi M. The impact of healthcare workers job environment on their mentalemotional health. Coping strategies: The case of a local general hospital. Health Psychol Res 2015; 3(1):1984. doi:10.4081/hpr.2015.1984.

2. Paker SK. Beyond motivation: Job and work design for Development, Health, Ambidexterity, and more. Annu Rev Psychol 2014; 65:66191.doi:10.1146/annurev-psych- 010213-115208.

3. LaMontagne AD, Keegel T, Shann CB, D'Souza R. An integrated approach to workplace mental health: an Australian feasibility study. Int $\mathrm{J}$ Ment Health Promot 2014; 16 (4): 205-15. https:// doi.org/10.1080/14623730.2014.931070.

4. Larsen AK, Holtermann A, Mortensen OS, Punnett L, Rod MH, Jørgensen MB. Organizing 
workplace health literacy to reduce musculoskeletal pain and consequences. BMC Nurs 2015; 14: 46. https://doi.org/10.1186/s12912-015-0096-4

5. Enns V, Currie S, Wang J. Professional autonomy and work setting as contributing factors to depression and absenteeism in Canadian nurses. Nurs Outlook 2015; 63(3): 269-77. doi: 10.1016/ j.outlook.2014.12.014.

6. Proctor RW, Van Zandt T. Human factors in simple and complex systems. $2^{\text {nd }}$ ed. Boca Raton, FL: CRC Press;2008.

7. Van Det MJ, Meijerink WJ, Hoff C, Totte ER, Pierie JP. Optimal ergonomics for laparoscopic surgery in minimally invasive surgery suites: a review and guidelines. Surg Endosc 2009; 23(6): 1279-1285. doi: 10.1007/s00464-008-0148-x.

8. Hancock PA. In search of vigilance: The problem of iatrogenically created psychological phenomena. Am Psychol 2013; 68(2): 97-109. doi: $10.1037 / a 0030214$.

9. Bhatnagar K, Srivastava K. Job satisfaction in health-care organizations. Ind Psychiatry J 2012; 21(1):75-78. doi:10.4103/0972-6748.110959.

10. Raptis DA, Schlegel A, Tschuor C, Clavien PA. Job satisfaction among young board-certified surgeons at academic centers in Europe and North America. Ann Surg 2012; 256(5):796-803. doi: 10.1097/SLA.0b013e31827386eb.

11. Moak JH, Gaspari RJ, Raio CC, Hart KW, Lindsell CJ. Motivations, job procurement, and job satisfaction among current and former ultrasound fellows. Acad Emerg Med 2010; 17(6):644-648. doi: 10.1111/j.1553-2712.2010.00749.x

12. Gibbs V, Edwards $H$. An investigation of sonographers unaffected by work-related musculoskeletal disorders. Ultrasound. 2012; 20(3):149154. https://doi.org/ 10.1258/ ult.2012.012014.

13. Morton B, Delf $P$. The prevalence and causes of MSI amongst Sonographers. Radiography. 2008; 14(3): 195-200. Doi: 10.1016/j.radi.2007.02.004

14. Saini N, Agrawal S, Bhasin SK, Bhatia MS, Sharma AK. Prevalence of stress among resident doctors working in Medical Colleges of Delhi. Indian J Public Health 2010; 54 (4): 219-23. DOI:10.4103/0019-557X.77266.

15. Szalma JL. On the application of motivation theory to human factors/ergonomics: Motivational design principles for human-technology interaction. Hum Factors. 2014; 56(8): 1453-1471.

16. Feng $Q$, Liu $S$, Yang $L$, Xie $M$, Zhang Q. the prevalence of and risk factors associated with Musculoskeletal Disorders among sonographers in Central China: A cross-sectional study. PLoS One. 2016; 11(10): e0163903. https://doi.org/ 10.1371/journal.pone.0163903.
17. Evans K, Roll S, Baker J. Work-Related Musculoskeletal Disorders (WRMSD) among registered diagnostic medical sonographers and vascular technologists: A representative sample. J Diagn Med Sonog 2009; 25(6):287-99. DOI: 10.1177/8756479309351748

18. Simonsen JG, Axmon A, Nordander G, Arvidsson I. Neck and upper extremity pain in sonographer's -Associations with occupational factors. Appl Ergon 2017; 58: 245-253. DOI: 10.1016/ j.apergo.2016.06.019.

19. Arvidsson I, Simonsen JG, Dahlqvist C, Axmon A, Karlson B, Björk $J$, et al. Cross-sectional associations between occupational factors and musculoskeletal pain in women teachers, nurses and sonographers. BMC Musculoskelet Disord 2016; 17:35. DOI 10.1186/s12891-016-0883-4.

20. Sommerich CM, Lavender SA, Evans K, Sanders E, Joines S, Lamar S, et al. Collaborating with cardiac sonographers to develop work-related musculoskeletal disorder interventions. Ergonomics 2016 Sep; 59(9):1193-204. doi: 10.1080/00140139.2015.1116613.

21. Claes F, Berger J, Stassijns G. Arm and neck pain in ultra-sonographers. Hum Factors 2015; 57 (2):238-45. doi:10.1177/0018720814547872.

22. Coffin C. Work-related musculoskeletal disorders in sonographers: a review of causes and types of injury and best practices for reducing injury risk. Reports in Medical Imaging 2014; 2014 (7):15-26. doi: 10.2147/rmi.s34724. DOI https:// doi.org/10.2147/ RMI.S34724.

23. Pelletier KR, Herman PM, Metz RD, Nelson CF. Health and medical economics applied to integrative medicine. Explore(NY) 2010; 6(2): 86-99. https:// doi.org/10.1016/j. explore. 2009.12.009.

24. Lim RC, Pinto C. Work stress, satisfaction and burnout in New Zealand Radiologists: Comparison of public hospital and private practice in New Zealand. J Med Imag Radiat Oncol 2009; 53 (2): 194-9. DOI: 10.1111/j.1754-9485.2009.02063.x.

25. Girgis A, Hansen V, Goldstein D. Are Australian oncology health professionals burning out? A view from the trenches. Eur $\mathrm{J}$ Cancer(Oxford England: 1990) 2008; 45(3): 393-399. DOI: 10.1016/ j.ejca.2008.09.029.

26. Marchand A, Demers A, Durand P. Does work really cause distress? The contribution of occupational structure and work organization to the experience of psychological distress. Soc Sci Med 2005; 61(1):1-14. doi:10.1016/ j.socscimed.2004.11.037.

27. Sumra MK, Schillaci MA. Stress and the Multiple-Role Woman: Taking a closer look at the 
"Superwoman". PLoS One 2015; 10(3): e0120952. doi: 10.1371/journal.pone.0120952.

28. Hughes RG, Rogers $A E$. Are you tired? Am J Nurs 2004;104(3):36-38.

29. Ugwu AC, Egwu OA, Nwobi IC, Oluware NF. Occupational stress among radiographers: the impact of sonography responsibility. Internet Journal of Medical Update 2009; 4 (1): 3-6.

30. Renner B, Schwarzer R. Risk and health behaviors: documentation of the Scales of the Research Project "Risk Appraisal Consequences in Korea" (RACK). International University Bremen \& Freie Universität Berlin: 2nd edition; 2005:1-55. Retrieved from http://www.gesundheitsrisiko.de/ docs/RACKEnglish.pdf. On July 05, 2018.

31. Morgeson FP, Humphrey SE. The Work Design Questionnaire (WDQ): Developing and validating a comprehensive measure for assessing job design and the nature of work. J Appl Psychol. 2006; 91(6):1321-1339. DOI: 10.1037/00219010.91.6.1321

32. Christian MS, Garza AS, Slaughter JE. Work
Engagement: A quantitative review and test of its relations with task and contextual performance. Pers Psychol. 2011; 64:89-136. DOI: 10.1111/ j.1744-6570.2010.01203.x

33. Punnett L, Cherniack M, Henning $R$, Morse $T$, Faghri $\mathrm{P}$, Faghri $\mathrm{P}$. The CPH-NEW Research Team. A conceptual framework for integrating workplace health promotion and occupational ergonomics programs. Public Health Rep 2009; 124 (Suppl 1): 16-25. https://doi.org/10.1177/ $00333549091244 S 103$

34. Muir M, Hrynkow P, Chase R, Boyce D, McLean $D$. The nature, cause, and extent of occupational Musculoskeletal injuries among sonographers. J Diagn Med Sonog 2004; 20 (5):317-25. doi/abs/10.1177/8756479304266737

35. Parker K. Despite progress, women still bear heavier load than men in balancing work and family. Fact Tank 2015. Retrieved on 02 January 2018 from http://www.pewresearch.org/facttank/2015/03/10/women-still-bear-heavier-loadthan-men-balancing-work-family/

AUTHOR AFFILIATION:

Dr. Uzma Zaidi (Corresponding Author)

Associate Professor of Clinical Psychology

Department of Health Sciences, College of Health and Rehabilitation Sciences

Princess Nourah bint Abdulrahman University, Riyadh, Saudi Arabia.

Email: uazaidi@pnu.edu.sa

Dr. Lina Fahmi Hammad

Associate Professor, Department of Radiological Sciences

College of Applied Medical Sciences

King Saud University, Riyadh, Saudi Arabia.

Dr. Salwa Saad Awad

Assistant Professor, Department of Rehabilitation Sciences

College of Health and Rehabilitation Sciences

Princess Nourah bint Abdulrahman University, Riyadh, Saudi Arabia.

Dr. Safaa Mostafa Ali Elkholi

Assistant Professor, Department of Rehabilitation Sciences

College of Health and Rehabilitation Sciences

Princess Nourah bint Abdulrahman University, Riyadh, Saudi Arabia.

Ms. Hind Diouri Qasem

Lecturer, Department of Health Sciences

College of Health and Rehabilitation Sciences

Princess Nourah bint Abdulrahman University, Riyadh, Saudi Arabia. 